\title{
ALTERAÇÕES CLÍNICAS, HISTOPATOLÓGICAS E ENZIMÁTICAS EM OVINOS INFECTADOS EXPERIMENTALMENTE POR Trypanosoma vivax
}

\author{
Katyane Sousa Almeida, ${ }^{1}$ Fagner Luiz Costa Freitas, ${ }^{2}$ José Hairton Tebaldi, ${ }^{3}$ Antonio Carlos \\ Alessi, ${ }^{4}$ Rosangela Zacarias Machado ${ }^{5}$ e Adjair Antonio Nascimento ${ }^{6}$ \\ 1. Doutora, professora da Universidade Federal do Tocantins. E-mail: katyanefreitas@gmail.com \\ 2. Doutor, professor da Universidade Federal do Tocantins \\ 3. Técnico da Universidade Estadual Paulista, Jaboticabal \\ 4. Doutor, professor da Universidade Estadual Paulista, Jaboticabal \\ 5. Doutora, professor da Universidade Estadual Paulista, Jaboticabal \\ 6. Doutor, professor da Universidade Estadual Paulista, Jaboticabal.
}

\section{RESUMO}

A presente pesquisa avaliou os sinais clínicos, as alterações histopatológicas e as variações em enzimas séricas em ovinos infectados experimentalmente por T. vivax. Para tanto utilizaram-se oito ovinos machos, sendo quatro destes para o grupo-testemunho e quatro infectados com $10^{5}$ tripomastigotas de T. vivax. Coletaram-se amostras de sangue em dois tempos antes da infecção e posteriormente em dias determinados, avaliando-se as dosagens de gamaglutamiltransferase, aspartatoaminotransferase, lactato desidrogenase, fosfatase alcalina e creatina quinase. Os animais foram examinados, diariamente, por parasitemia e aos 120 dias após infecção (dpi) foram eutanasiados e necropsiados, com estudo histopatológico de fígado, rins, baço, coração, linfonodos, cérebro, pulmão e testículos. Para a análise estatística, empregouse o teste de Wilcoxon a 5\% de probabilidade. Os sinais clínicos encontrados foram: apatia, palidez das mucosas, aumento de linfonodos superficiais, secreção nasal e elevação da temperatura retal, diarreia esporádica e sinais nervosos (bruxismo e incoordenação). Houve alterações significativas em todos os parâmetros bioquímicos e histopatológicos avaliados nos animais infectados. Dessa forma, a amostra de T. vivax procedente da Paraíba é capaz de causar alterações enzimáticas, clínicas e histológicas importantes, comprometendo a funcionalidade dos órgãos afetados e resultando em disfunção metabólica animal.

PALAVRAS-CHAVES: Bioquímicos, enzimas, histopatologia, pequeno ruminante, Trypanosomatidae, sinais clínicos.

\section{ABSTRACT}

\section{CLINICAL, HISTOPATHOLOGICAL AND ENZYMATIC CHANGES IN SHEEP EXPERIMENTALLY INFECTED WITH Trypanosoma vivax}

This present research evaluated the clinical signs, histopathological and enzymatic changes in sheep experimentally infected with $T$. vivax. For this evaluation, eight male sheep, four in the control group and four infected with $10^{5} \mathrm{~T}$. vivax trypomastigotes were used. Blood samples were collected twice before infection and on certain days after infection, evaluating the serum levels of gamma-glutamyltransferase, aspartate aminotransferase, lactate dehydrogenase, alkaline phosphatase and creatine kinase. The animals were examined daily for parasitaemia, and 120 days after infection (dpi) the animals were euthanized and necropsied with posterior liver, kidney, spleen, heart, lymph nodes, brain, lung and testicles histopathology. Wilcoxon test at $5 \%$ probability was used for the statistical analysis. The following clinical signs were found: apathy, pallor of mucous membranes, increase of superficial lymph nodes, nasal discharge and elevated rectal temperature, occasional diarrhea and nervous signs (bruxism and incoordination). Significant changes in all biochemical parameters and histopathological parameters were found in infected animals, thus the T. vivax sam- 
ple found in Paraíba, Brazil, can cause changes on enzyme levels besides clinical and important histological changes, compromising the functionality of the affected organs and resulting in metabolic dysfunction.

KEYWORDS: Biochemical, clinical signs, enzymes, histopathology, small ruminant, Trypanosomatidae.

\section{INTRODUÇÃO}

T. vivax é responsabilizado por perdas econômicas na pecuária, por provocar abortamentos, infertilidade, perda na condição física, diminuição da produção e mortalidade, além dos custos com diagnóstico e tratamento causados pela enfermidade (SEIDL et al., 1999).

No Brasil, foi diagnosticado um surto de tripanossomíase em bovinos por T. vivax na região de Poconé, Pantanal do Estado do Mato Grosso, sendo o parasito responsabilizado por perdas econômicas na região, com informação de que haveria a possibilidade de disseminação pelo território nacional (SILVA et al., 1996). Confirmando essa observação, T. vivax vem se expandindo pelo território brasileiro, sendo encontrados surtos na Paraíba (BATISTA et al., 2008), Tocantins (LINHARES et al., 2006) e Maranhão (GUERRA et al., 2008), porém poucos estudos descrevem a patogenicidade da amostra do protozoário e principalmente são esquecidos os aspectos referentes às alterações bioquímicas causadas por ele. $\mathrm{O}$ estudo dos sinais clínicos, histopatologia e da função hepática por meio das dosagens das enzimas alanina aminotransferase (ALT) e fosfatase alcalina (ALP) associadas a gamaglutamiltransferase (GGT) poderia contribuir para um melhor entendimento da enfermidade, auxiliando no diagnóstico clínico e até mesmo para instituir um tratamento adequado com uso de hepatoprotetores quando necessário.

Além disso, um aspecto importante é o comprometimento muscular observado em animais infectados com Trypanosoma spp. FINOL et al. (2001) e CADIOLI (2005), em pesquisa realizada em ratos infectados com $T$. evansi, verificaram que o sistema muscular parecia ser alvo importante do patógeno, pois os animais apresentavam emagrecimento progressivo até caquexia, com perda do tônus muscular e transtornos motores, caracterizados por movimentos lentos até a incapacidade de sustentação do próprio peso nos membros pélvicos, evoluindo para paraplegias atribuídas às lesões que envolvem o sistema nervoso central e o muscular.
Para o estudo da patogenicidade dos isolados de campo são necessários, além da avaliação da enfermidade em animais portadores da infecção natural, estudos realizados mediante infecção experimental e em decorrência da suscetibilidade de caprinos e ovinos à tripanossomíase por T. vivax, frequentemente utilizadas para obtenção de conhecimentos dos aspectos fundamentais das manifestações clínica e patológica da infecção (BATISTA et al., 2008).

Dessa forma, o presente trabalho teve por objetivo verificar os sinais clínicos, as alterações histopatológicas e as variações em enzimas séricas em ovinos infectados experimentalmente por T. vivax com a amostra procedente da Paraíba.

\section{MATERIAL E MÉTODOS}

O experimento foi realizado no Setor de Enfermidades Parasitárias dos Animais, Departamento de Medicina Veterinária Preventiva e Reprodução Animal da Faculdade de Ciências Agrárias e Veterinárias (FCAV/UNESP/Jaboticabal).

Para preparação do inóculo, inocularam-se $2 \mathrm{~mL}$ de sangue com aproximadamente $1,95 \times 10^{5}$ tripomastigotas de $T$. vivax por via intravenosa, em um ovino macho, sem raça definida, de um ano de idade, visando à multiplicação do agente utilizado para infecção dos animais do experimento. A amostra de T. vivax foi obtida de surto em bovinos na região de Catolé do Rocha, Paraíba, e cedida pela Universidade Federal da Paraíba.

Para montagem do grupo experimental foram utilizados oito ovinos machos, com um ano de idade e sem raça definida, que passaram por um período de quarentena para avaliações clínicas e parasitológicas, incluindo a pesquisa de anticorpos anti-T. vivax pela Reação de Imunofluorescência Indireta (RIFI) descrita por AQUINO et al. (1999) e exames hematológicos, bioquímicos e coprológicos. Os animais hígidos foram mantidos em baias individuais, suspensas e teladas, e alimentados com silagem de milho, água ad libitum e suplementados com sal mineral. Dividiram-se os animais, aleatoriamente, em dois grupos, sendo quatro 
ovinos destinados ao grupo-testemunho $(\mathrm{C} 1, \mathrm{C} 2, \mathrm{C} 3 \mathrm{e}$ C4) e quatro infectados (I1, I2, I3 e I4) com $1 \mathrm{~mL}$ de sangue com aproximadamente $10^{5}$ tripomastigotas de T. vivax por via intravenosa.

Para realização da parasitemia foi colhido $0,5 \mathrm{~mL}$ de sangue da veia jugular externa, em frascos contendo EDTA a 10\%, diariamente e pela manhã, dos animais infectados até os 120 dias após infecção (dpi). A contagem dos parasitos foi realizada por meio da metodologia descrita por BRENER (1961). Durante a colheita de sangue, verificaram-se os aspectos das mucosas aparentes, comportamento, palpação dos linfonodos superficiais e aferição da temperatura retal.

Para os exames bioquímicos foram colhidos $5 \mathrm{~mL}$ de sangue, sem anticoagulante, da veia jugular externa de cada animal dos grupos testemunho e infectado, para separação do soro, que permaneceu sob temperatura de $-20^{\circ} \mathrm{C}$ para realização dos exames bioquímicos após sete dias. As colheitas foram realizadas aos quatorze e sete dias antes da infecção, sendo os soros usados para estabelecimento dos valores de referência, máximos e mínimos, para cada parâmetro avaliado, seguindo-se no 5, 7, 9, 11, 13, 15, 20, 30, 45, $60,75,90,105$ e 120 dpi.

As dosagens das enzimas gamaglutamiltransferase (GGT), aspartatoaminotransferase (AST), lactato desidrogenase (LDH), fosfatase alcalina (ALP) e creatina quinase $(\mathrm{CK})$ foram realizadas pelo método cinético, utilizando kits comerciais (Labtest ${ }^{\circledR}$ Diagnóstica, Belo Horizonte, MG) e lidos em espectofotômetro (LabQuest ${ }^{\circledR}$ Diagnóstica, Belo Horizonte, MG).

Após os 120 dpi, os animais foram eutanasiados e necropsiados, sendo fragmentos de fígado, rins, baço, coração, linfonodos, cérebro, pulmão, testículos e glândulas adrenais retirados e fixados em solução tamponada de formaldeído a $10 \%$, para confecção de lâminas histológicas, coradas por hematoxilina e eosina.

Utilizou-se o teste de Wilcoxon, ao nível de 5\% de probabilidade, para avaliação das variáveis relacionadas às dosagens bioquímicas. Todas as análises foram realizadas utilizando-se o programa estatístico SAEG - Sistema para Análises Estatísticas.

\section{RESULTADOS E DISCUSSÃO}

O período pré-patente (PPP) foi de um dia no animal I4 e nos outros animais de dois dias; a parasi- temia foi intermitente e com variação de intensidade em todos os animais até os 120 dpi. Encontraram-se o seguintes sinais clínicos nos ovinos infectados experimentalmente pelo T. vivax: apatia, palidez das mucosas, aumento de linfonodos superficiais, corrimento nasal, elevação da temperatura retal entre os 10 ao 18 dpi de até $41,5^{\circ} \mathrm{C}$. Após esse período, houve uma redução da temperatura, permanecendo dentro dos valores de normalidade para a espécie, com um novo período de elevação entre os 86 e 92 dpi. Após os 85 dpi, houve diarreia esporádica em todos os animais e sinais nervosos em dois ovinos caracterizados por bruxismo e incoordenação motora.

Os sinais clínicos observados nos ovinos estão de acordo com os relatos da maioria dos trabalhos desenvolvidos com T. vivax (MORAES, 2001; PELLÍN et al., 2003; BATISTA et al., 2006). BATISTA et al. (2006) verificaram ainda respiração ofegante e sinais de cansaço após esforço, e um animal apresentou depressão, fraqueza, decúbito lateral e morte aos 75 dpi.

Alguns autores acreditam que a patogenicidade do T. vivax em infecções experimentais deve-se a grandes quantidades de inóculo utilizadas nos experimentos (DESQUENES \& GARDINER, 1993). No entanto, em alguns trabalhos, mesmo com grandes inóculos, não foram verificados sinais clínicos (SCHENK et al., 2001), levando a crer que, realmente, existam diferenças na patogenicidade entre diferentes amostras e/ou na susceptibilidade animal. Além disso, trabalhos realizados com a mesma amostra, porém com inóculos diferentes, obtiveram resultados semelhantes (BATISTA et al., 2006; ALMEIDA et al., 2008), demonstrando que as diferenças na patogenicidade do $T$. vivax pode estar associada ao animal, tendo em vista raça, idade, alimentação e fatores ambientais.

Nos animais infectados, todas as enzimas estudadas (GGT, AST, ALP, LDH e CK) apresentaram diminuição em comparação aos testemunhos $(p<0,05)$ e com valores abaixo da referência para GGT aos 20 , 30 e 120 dpi; para ALP aos 60 e 120 dpi; para LDH aos 13, 20, 45, 60 e após o $105 \mathrm{dpi}$; para AST após nove dpi; e para CK aos 13 e 15 dpi e após 30 dpi até o final do período experimental (Tabela 1), demonstrando haver uma tendência à diminuição dessas enzimas nos animais infectados.

As enzimas AST, ALP e GGT, que geralmente estão aumentadas quando se tem um dano hepático, 
demonstraram, no presente estudo, uma diminuição. Em bovinos infectados com T. vivax, a AST permaneceu inalterada (MORAES, 2001; SCHENK et al., 2001) ou apresentou incremento inicial (até 6 dpi) com posterior decréscimo (KADIMA et al., 2000). O aumento ocorreu não por danos teciduais, mas pelo fato de o parasito secretar parte dos seus metabólicos (AST e ALT) dentro da circulação sanguínea, o que foi observado por GRAY (1961) em suspensão de tripanossomas; e o decréscimo, associado à alteração hepática desenvolvida com a progressão da doença (KADIMA et al., 2000), conforme observado na presente pesquisa. Para GGT, SCHENK et al. (2001) observaram um aumento em relação ao controle, mas dentro dos valores normais para bovinos.

Em relação à ALP, sua diminuição também foi observada em bovinos infectados com T. vivax (MORAES, 2001). Em estudo com cultura de placenta, que avaliou a ação de tripomastigotas sobre a ALP, foi demonstrado um aumento da enzima aos 150 minutos e decréscimo após esse período, sendo sugerido que o decréscimo seja resultante da interação do parasito com a membrana placentária (FRETES \& FABRO, 1990). Dessa forma, se a interação também puder ocorrer entre $T$. vivax e o hepatócito, resultaria na redução dessa enzima, explicando o observado nos ovinos infectados deste estudo.

A diminuição na concentração de AST pode também estar relacionada à alteração muscular, visto que ela não é hepato-específica assim como a LDH, que possui cinco isoenzimas. Mas quando associadas suas dosagens e as da enzima CK, caracterizam uma alteração muscular. Dessa forma, esses achados sugerem haver lesão muscular em ovinos infectados com Trypanosoma vivax. Segundo CABRAL et al. (1999), a diminuição da atividade de AST e CK pode estar relacionada a um desequilíbrio metabólico, vindo a ocasionar um funcionamento anormal do órgão onde ela tem sua maior atividade. Além disso, conforme TOMIMOTO et al. (1993), uma diminuição da atividade da CK pode prejudicar a homeostase energética cerebral, contribuindo para a morte celular, resultando em neurodegeneração.

Todos os órgãos dos animais infectados apresentaram alterações no exame histopatológico como hiperplasia de órgãos linfoides e infiltrados inflamatórios de diferentes intensidades em diversos tecidos, conforme apresentado na Tabela 2.
As alterações histopatológicas em infecções por T. vivax são frequentemente observadas, acometendo diversos órgãos com lesões de intensidades diferentes. No trabalho realizado em ovinos, com a mesma amostra usada no presente estudo, foram observadas hiperplasia do baço, linfadenite eosinofílica e miocardite (BATISTA et al., 2006). Já no trabalho realizado por PAIVA et al. (2000a) em bovinos infectados experimentalmente com amostra de T. vivax do Pantanal, encontraram-se pequeno aumento no tamanho do baço e do fígado, glomerulonefrite e miocardite não supurativa multifocal.

A fisiopatologia das lesões inflamatórias e degenerativas causadas pelos tripanossomas não é bem determinada e/ou conhecida, e supõe-se que haja deposição de imunocomplexos nos diversos tecidos e, desse modo, as hemácias sensibilizadas por tais complexos seriam destruídas pelo sistema fagocíticomononuclear do hospedeiro (TIZARD et al., 1978), e/ ou o próprio parasito teria causado danos aos tecidos do espaço extravascular pela inerente movimentação (VAN DEN INGH et al., 1976).

A presença dos tripanossomas no coração, conforme observado no presente estudo, é possível, pois esse protozoário já foi encontrado em tecido cardíaco (KIMETO et al., 1990). As alterações histológicas observadas no coração dos ovinos, caracterizadas por infiltrado multifocal de células mononucleares no interstício, são semelhantes às descritas por MASAKE (1980) em bovinos e caprinos infectados experimentalmente por T. vivax. KIMETO et al. (1990) também descreveram lesões hemorrágicas com infiltrado mononuclear, atribuindo a reação inflamatória no miocárdio à presença extravascular do T. vivax.

WHITELAW et al. (1988) demonstraram $T$. vivax no fluido cérebro-espinhal, causando coroidite, meningite e meningoencefalite. Nas observações do presente estudo as mesmas lesões estiveram presentes.

As alterações encontradas nos testículos dos ovinos podem afetar diretamente a fertilidade dos animais, demonstrando que não só as fêmeas infectadas com $T$. vivax possuem problemas reprodutivos. Conforme SEKONI (1994), as alterações reprodutivas em machos infectados por tripanossoma incluem perda da libido, retardamento da puberdade e má qualidade do sêmen. 


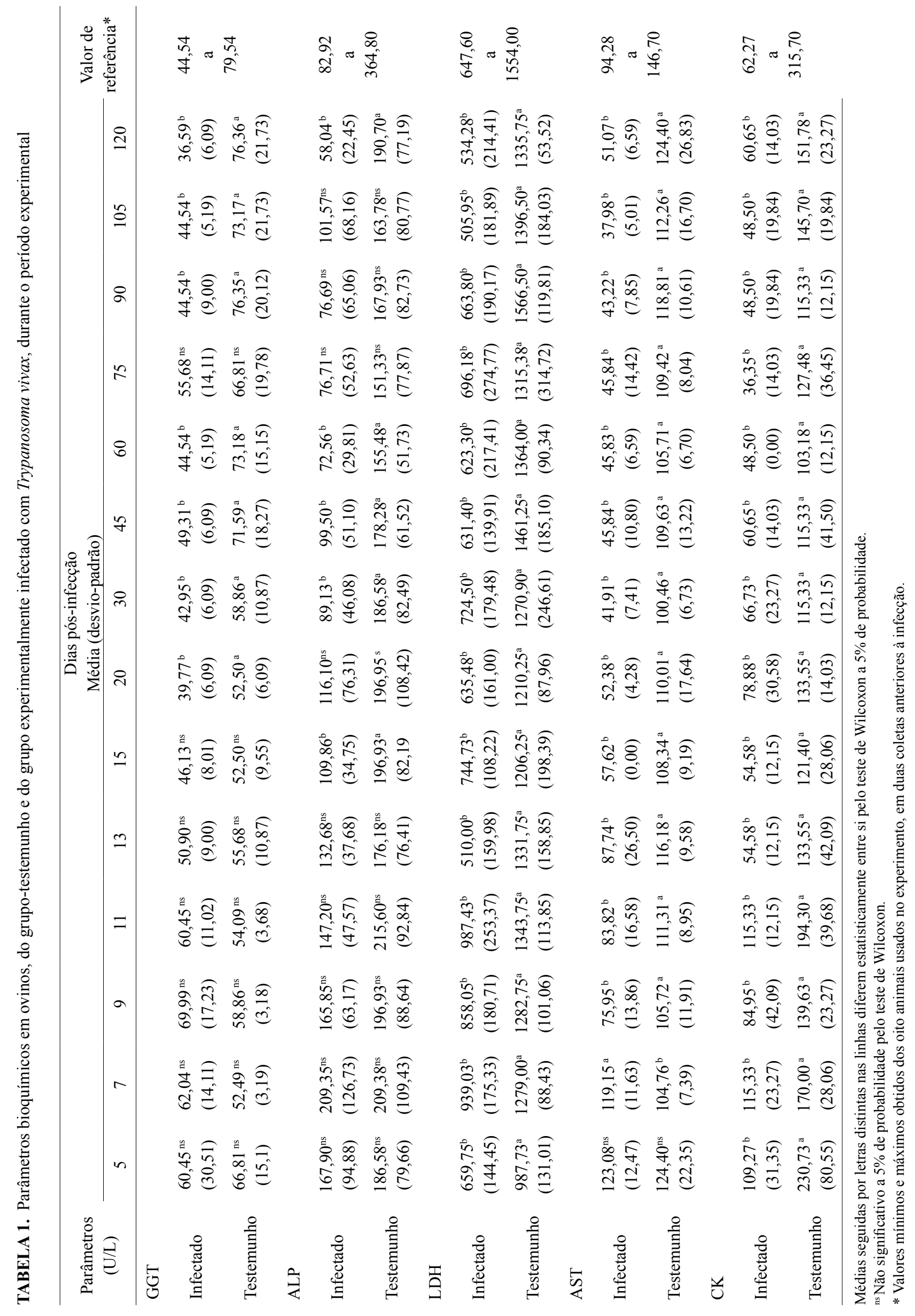




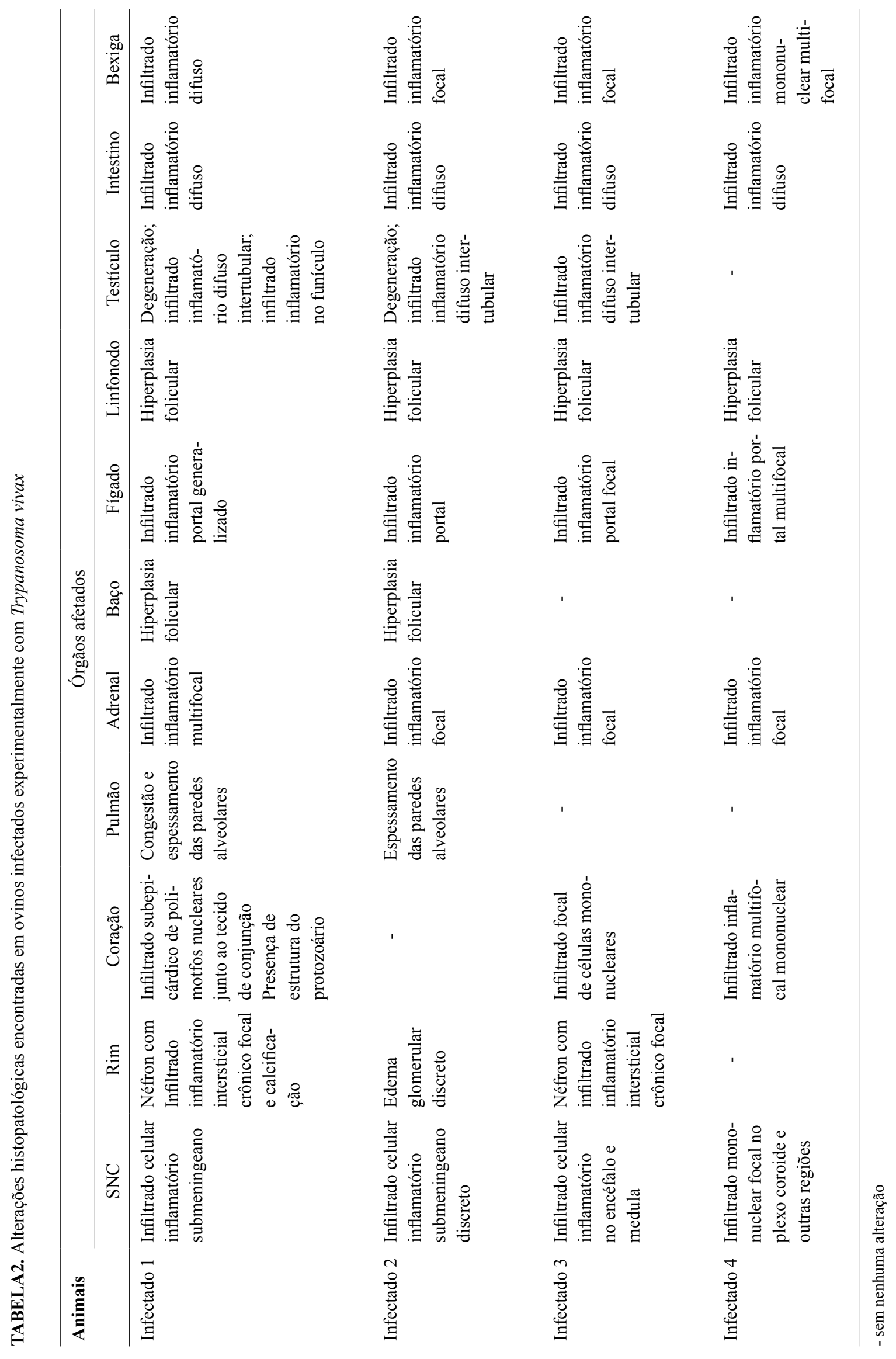


PAIVA et al. (2000b) verificaram infiltrado inflamatório no rim de animais positivos para $T$. vivax, mas como apresentavam também outras alterações compatíveis com intoxicação por Solanum malacoxylon, acreditaram dever-se a ela a lesão renal. No entanto, achados semelhantes no presente estudo sugerem que as lesões poderiam também ser causadas por T. vivax.

As lesões hepáticas, observadas histologicamente e mais visivelmente no aspecto funcional pela alteração nas enzimas estudadas, podem ocorrer pela produção de uma hepatotoxina produzida pelos tripanossomas (LUMSDEN et al., 1972) ou por um autoanticorpo hepático verificado por SEED \& GAM (1967) em infecção por T. brucei.

\section{CONCLUSÃO}

A amostra de $T$. vivax procedente da Paraíba é capaz de causar alterações enzimáticas, clínicas e histológicas importantes, comprometendo a funcionalidade dos órgãos afetados e resultando em disfunção metabólica animal.

\section{REFERÊNCIAS}

ALMEIDA, K. A.; FREITAS, F. L. C.; JORGE, R. L. N.; NOGUEIRA, C. A. S.; MACHADO, R.Z.; NASCIMENTO, A.A. Aspectos hematológicos da infecção experimental por Trypanosoma vivax em ovinos. Ciência Animal Brasileira, v. 9, n. 4, p. 1121-1127, 2008.

AQUINO, L. P. C. T.; MACHADO, R. Z.; ALESSI, A. C.; MARQUES, L. C.; CASTRO, M. B.; MALHEIROS, E. B. Clinical, parasitological and immunological aspects of experimental infection with Trypanosoma evansi in dogs. Memórias do Instituto Oswaldo Cruz, v. 94, n. 2, p. 255-260, 1999.

BATISTA, J. S.; RIET-CORREA, F.; BARBOSA, R. C.; GUERRA, J. L. Infecção experimental por Trypanosoma vivax em ovinos. Pesquisa Veterinária Brasileira, v. 26, n. 1, p. 31-37, 2006.

BATISTA, J. S.; BEZERRA, F. S. B.; LIRA, R. A.; CARVALHO, J. R. G.; ROSADO NETO, A. M.; PETRI, A. A.; TEIXEIRA, M. M. G. Aspectos clínicos, epidemiológicos e patológicos da infecção natural em bovinos por Trypanosoma vivax na Paraíba. Pesquisa Veterinária Brasileira, v. 28, n. 1, p. 63-69, 2008.

BRENER, Z. Contribuição ao estudo da terapêutica experimental da doença de Chagas. 1961. Tese (Livre-Docência) Universidade Federal de Minas Gerais, Faculdade de Odontologia e Farmácia, 1961.
CABRAL, M. M.; SILVEIRA, A. C.; ARRIGONI, M. B.; COSTA, C.; OLIVEIRA, H. N.; CHARDULO, L. A. L. Efeito de diferentes níveis de salinomicina sobre o desempenho e funções enzimáticas de ovinos em regime de confinamento. Ciência e Agrotecnologia, v. 23, n. 4, p. 968-972, 1999.

CADIOLI, F. A. Estudos metabólicos, hematológicos e anatomopatológicos em ratos Wistar infectados com Trypanosoma evansi. 2005, 92 f. Tese (Doutorado) - Universidade Estadual Paulista, Faculdade de Ciências Agrárias e Veterinárias, Jaboticabal, 2005.

DESQUENES, M.; GARDINER, P. R. Epidémiologie de la trypanosomose bovine (Trypanosoma vivax) en Guyane française. Revue d'élevage et de Médecine Vétérinaire des Pays Tropicaux, v. 46, n. 3, p. 463-470, 1993.

FINOL, H. J.; BOADA-SUCRE, A.; ROSSI, M.; TEJERO, F. Skeletal muscle ultrastructural pathology in mice infected with Trypanosoma evansi. Journal of Submicroscopic Cytology and Pathology, v. 33, n. 1, p. 65-71, 2001.

FRETES, R. E.; FABRO, S. P. Trypanosoma cruzi: modification of alkaline phosphatase activity induced by trypomastigotes in cultured human placental villi. Revista do Instituto de Medicina Tropical de São Paulo, v. 32, n. 6, p. 403-408, 1990.

GRAY, A. R. Serum transaminase levels in cattle and sheep infected with Trypanosoma vivax. Experimental Parasitology, v. 14, p. 374-381, 1961.

GUERRA, R. M. S. N. C.; FEITOSA JR, A. B.; SANTOS, H. P.; ABREU-SILVA, A. L.; SANTOS, A. C. G. Biometry of Trypanosoma vivax found in a calf in the state of Maranhão, Brazil. Ciência Rural, v. 38, n. 3, p. 833-835, 2008.

KADIMA, K. B.; GYANG, E. O.; SAROR, D. I.; ESIEVO, K. A. N. Serum biochemical values of Trypanosoma vivax-infected cattle and the effects of lactose in saline infusion. Veterinary Archives, v. 70, p. 67-74, 2000.

KIMETO, B. A.; MUGERA, G. M.; NYAGA, P. N. Haemorrhagic pancarditis in cattle infected with Trypanosoma vivax. Veterinary Parasitology, v. 34, p. 295-301, 1990.

LINHARES, G. F. C.; DIAS FILHO, F. D.; FERNANDES, P. R.; DUARTE, S. C.; Tripanossomíase em bovinos no município de Formoso do Araguaia, Tocantins. Relato de Caso. Ciência Animal Brasileira, v. 7, n. 4, p. 455-460, 2006.

LUMSDEN, R. D.; MARCIACQ, Y.; SEED, J. R. Trypanosoma gambiense: cytophatologic changes in guinea pig hepatocytes. Experimental Parasitology, v. 32, p. 369-389, 1972.

MASAKE, R.A. The pathogenesis of infection with Trypanosoma vivax in goats and cattle. Veterinary Record, v. 13, p. 551-557, 1980. 
MORAES, M. A. V. Trypanosoma vivax: infecção experimental em bovinos (Bos indicus). 2001. 104 f. Tese (Mestrado) - Universidade Estadual Paulista, Faculdade de Ciências Agrárias e Veterinárias, Campus de Jaboticabal, 2001.

PAIVA, F.; LEMOS, R. A. A.; NAKASATO, L.; BRUM, K. B.; BERNADO, K. C.; MADRUGA, C. R.; SCHENK, M. A. Trypanosoma vivax em bovinos no Pantanal do Estado de Mato Grosso do Sul, Brasil: II - Inoculação Experimental. Revista Brasileira de Parasitologia Veterinária, v. 9, n. 2, p. 143-148, 2000a.

PAIVA, F.; LEMOS, R. A. A.; NAKASATO, L.; MORE, A. E.; BRUM, K. B.; BERNADO, K. C. Trypanosoma vivax em bovinos no Pantanal do Estado de Mato Grosso do Sul, Brasil: I - Acompanhamento clínico, laboratorial e anatomopatológico de rebanhos infectados. Revista Brasileira de Parasitologia Veterinária, v. 9, n. 2, p. 135-141, 2000b.

PELLÍN, C. E. S.; GONZÁLEZ, F. A.G.; BALDIZÁN, G.; LINAREZ, Y. F. F. M. Comportamiento parasitológico, clínico y hematológico en ovinos infectados experimentalmente con un aislado venezolano de Trypanosoma vivax. Veterinaria Tropical, v. 28, p. 79-92, 2003.

SCHENK, M. A. M.; MENDONÇA, C. L.; MADRUGA, C. R.; KOHAYAGAWA, A.; ARAÚJO, F. R. Avaliação clínicolaboratorial de bovinos Nelore infectados experimentalmente com Trypanosoma vivax. Pesquisa Veterinária Brasileira, v. 21, n. 4, p. 157-161, 2001.

SEED, J. R.; GAM, A. A. The presence of antibody to a normal liver antigen in rabbits infected with Trypanosoma gambiense. Journal Parasitology, v. 53, p. 946-950, 1967.
SEIDL, A.; DÁVILA, A. M. R.; SILVA, R. A. M. S. Estimated financial impact of Trypanosoma vivax on the Brazilian Pantanal and Bolivian Lowlands. Memórias do Instituto Oswaldo Cruz, v. 94 , n. 2, p. 269-272, 1999.

SEKONI, V. O. Reproductive disorders caused by animal trypanosomiases: A review. Theriogenology, v. 42, n. 4, p. 557-570, 1994.

SILVA, R. A. M. S.; SILVA, J. A.; SCHNEIDER, R. C.; FREITAS, J.; MESQUITA D. P.; MESQUITA T. C.; RAMIREZ, L.; DAVILA, A. M. R.; PEREIRA, M. E. B. Outbreak of trypanosomiasis due to Trypanosoma vivax (Ziemann, 1905) in bovines of the Pantanal, Brazil. Memórias do Instituto Oswaldo Cruz, v. 5, p. 561-562, 1996.

TIZARD, I. A. N.; NIELSEN, K. H.; SEED, J. R.; HALL, J. E. Biologically active products from African Trypanosomes. Microbiological Reviews, v. 42, n. 4, p. 661-681, 1978.

TOMIMOTO, H.; YAMAMOTO, K.; HOMBURGER, H. A.; YANAGIHARA, T. Immunoelectron microscopic investigation of creatine kinase BB-isoenzyme after cerebral ischemia in gerbils, Acta Neuropathologica, v. 86, n. 5, p. 447-455, 1993.

VAN DEN INGH, T. S. G. A. M.; ZWART, D.; SCHOTMAN, A. J. H.; VAN MIERT, A. S. J. P. A. M.; VEENENDAAL, G. H. The pathology and patogenesis of Trypanosoma vivax infection in the goat. Research in Veterinary Science, v. 21, p. 264-270, 1976.

WHITELAW, D. D.; GARDINER, P. R.; MURRAY, M. Extravascular foci of Trypanosoma vivax in goats: the central nervous system and aqueous humor of the eye as potential sources of relapse infections after chemotherapy. Parasitology, v. 97, n. 1, p. 51-62, 1988. 